\title{
Editorial: Thank you all for the timely Journal we have
}

\author{
Ganapati P. Patil
}

Published online: 11 November 2011

(C) Springer Science+Business Media, LLC 2011

\section{Introduction and motivation for thank you all}

It is now some forty years that I have been in foundational initiatives and leadership roles for statistical ecology and environmental statistics, of which some 20 years devoted to founding and editing of this Journal, with its editorial headquarters at the Penn State Center for Statistical Ecology and Environmental Statistics, of which I have been the founding director for its disciplinary and cross-disciplinary research, training, and outreach. Each one of these undertakings has been quite successful and satisfying indeed. Thank you all of the triadic statistics, ecology, and environment community for your enthusiastic participation and cooperation. It is now appropriate in these beginnings of the present century to hand over this wonderful Journal to you all, with Pierre Dutilleul and Ashis Sengupta as editor-in chiefs. Let us continue to be in good shape, continuing our mutual interest and quality attention in a timely manner. I will be also glad to be on hand for any special events and issues.

On this significant transition, it is natural that we look back with a forward look, starting especially with our versatile renowned editorial community, and recalling our timely special issues with matching guest editors. Also, we may wish to make a note of the inspirational events and articles, published from time to time, as listed selectively in the references at the end for our individual and collective reflection.

G. P. Patil (凶)

Department of Statistics, Center for Statistical Ecology and Environmental Statistics,

Penn State University, University Park, PA 16801, USA

e-mail: gpp@stat.psu.edu 


\section{Versatile cross disciplinary editorial community of the Journal}

\section{Editor-in-Chief}

Ganapati P. Patil, Center for Statistical Ecology and Environmental Statistics, Department of Statistics, Penn State University, University Park, PA, 16801, USA

Deputy Editor-in-Chiefs

Timothy Gregoire, School of Forestry and Environmental Studies, Yale University, CT.; Wolfgang Urfer, Department of Statistics, University of Dortmund, Germany.

\section{Managing Editors}

Charles Taillie, Penn State University; Stephen Rathbun, University of Georgia

\section{Editorial Secretary}

Barbara Freed, Penn State University

\section{Publishing Editor}

Melinda Paul, Springer, Environmental Science Area

Advisory Board

John Bailar, Department of Epidemiology and Biostatistics, McGill University, Montreal, Canada, Vic Barnett, School of Computing and Mathematics, Nottingham Trent University, UK; Peter Bartelmus, Statistical Division of the United Nations, New York, Lynne Billard, Department of Statistics, University of Georgia; S. T. Buckland, School of Mathematics and Statistics, St. Andrews, UK; Raymond Carroll, Department of Statistics, Texas A\&M University; George Casella, Department of Statistics, University of Florida; Lawrence H. Cox, National Center for Health Statistics, Centers for Disease Control, MD; A. H. El-Shaarawi, National Water Research Institute, Burlington, Canada; Alan Gelfand, ISDS, Duke University, NC; Timothy G. Gregoire, School of Forestry and Environmental Studies, Yale University, CT; David Hoel, Biometry and Epidemiology, Medical University of South Carolina; William F. Hunt, Jr., Office of Air Quality Plans and Standards, USEPA, NC., J. N. R. Jeffers, Natural Environment Research Council, UK., Nan Laird, Dept. of Biostatistics, Harvard School of Public Health, Boston, MA., Pierre Legendre, Dépt de Sci Biologiques, Université de Montréal, Canada; Simon Levin, Department of Ecological and Evolutionary Biology, Princeton University, NJ; Rick A. Linthurst, Office of the Inspector General U.S. EPA, NC; Marc Mangel, Department of Applied Math \& Statistics, UCSC, CA; K. V. Mardia, Department of Statistics, University of Leeds, UK; K. Matusita, Institute of Statistical Mathematics, Tokyo, Japan, Sir Robert May, Department of Zoology, University of Oxford, UK; Laszlo Orloci, Department of Plant Sciences, University of Western Ontario, Canada; Joe Perry, Department of Entomology \& Nematology, Rothamsted Exp Station, UK; Christopher Portier, Laboratory of Quant. \& Comp. Biology, NIEHS, NC; Jonathan Plaut, Worldwide Environmental Programs, Allied Signal Inc., NJ., Paul Portney, Resources for the Future, Washington, DC., John W. Pratt, Managerial Economcs, Harvard Business School, Boston, MA., C. R. Rao, Department of Statistics, Penn State University, PA; Charles A. Rohde, Dept of Biostatistics, Johns Hopkins University, Baltimore, MD., N. Phillip Ross, Office of 
Environment Information, U.S EPA, Washington, DC; Orazio Rossi, Dipartimento di Scienze Ambientali, Università di Parma, Italy; Louise M. Ryan, Dana-Farber Cancer Institute, Harvard School of Public Health, MA; Jerome Sacks, National Institute of Statistical Sciences, RTP., NC., P. K. Sen, Department of Biostatistics, University of North Carolina; Daniel Simberloff, Department of Ecology \& Evolution Biology, University of Tennessee; Michael Sissenwine, National Marine Fisheries Service, NOAA, Woods Hole, MA., Daniel Solomon, Dept of Statistics, North Carolina State University, Raleigh, NC., Wolfgang Urfer, Department of Statistics, University of Dortmund, Germany; James Ware, Dept. of Biostatistics, Harvard School of Public Health, MA, William E. Waters, Dept of Ferestry and Resource Management, University of California, Berkeley, CA., Ronald Wyzga, Electric Power Research Institute, CA. James V. Zidek, Department of Statistics, University of British Columbia, Canada.

\section{Editorial Board}

John Beddington, Renewable Resources Assessment Group, Imperial College, London, UK., Helmut Beran, Institute for Systems Sciences, University of Linz, Austria, Lucio Barabesi, Dipart di Metodi Quant, Univ degli Studi di Siena, Italy; Harold E. Burkhart, Dept. of Forestry, VPI\&SU $<$ VA., Raymond Carroll, Dept. of Statistics, Texas A\&M U., TX., George Casella, Biometrics Unit, Cornell U, NY., George Christakos, Department of Environmental Science \& Engineering, University of North Carolina; Brian C. Dennis, Fish and Wildlife Resources, University of Idaho; Darryl J. Downing, Oak Ridge National Laboratory, TN., Richard O. Gilbert, Batelle Pacific Northwest Labs, WA., Peter Guttorp, Department of Statistics, University of Washington; Andre G. Journel, Dept of Geology and Environmental Sciences, Stanford U., CA., Ralph Kodell, Division of Biom \& Risk Assessment, National Center for Toxic Research, AR; Diane Lambert, Bell Labs, NJ., Andrew B. Lawson, Department of Epidemiology \& Biostatistics, University of South Carolina; Subhash Lele, Department of Math Sciences, University of Alberta, Canada; Ian B. MacNeil, U of Western Ontario, Canada, B. F. J. Manly, Western EcoSystems Technology, Inc., Laramie, WY; James H. Matis, Department of Statistics, Texas A\&M University; Roger Mead, U of Reading, UK., Donald E. Myers, Department of Mathematics, University of Arizona; Vijayan Nair, Bell Labs, NJ., Anthony R. Olsen, National Health \& Env. Effects Research Lab, U.S. EPA, OR; Laszlo Orloci, Dept of Plant Sciences, U of Western Ontario, Canada, Walter W. Piegorsch, Interdisciplinary Program in Statistics, University of Arizona; Fred Ramsey, Oregon State U, OR., Bo Ranneby, Centre of Biostochastics, Swedish University of Agri. Science, Sweden; Paul D.Sampson, Department of Statistics, University of Washington; Josef Sedransk, Biometry and Statistics, SUNY, Albany, NY., B. K. Sinha, Department of Math \& Statistics, University of Maryland; Abe Silvers, EPRI, CA., Eric P. Smith, Department of Statistics, VPI\&SU, VA; Andrew Solow, Woods Hole Oceanographic Institution, MA; Cliff Spiegelman, Texas A\&M, TX., Stephen V. Stehman, Department of Forestry, State University of New York; Alfred Stein, Wageningen University, The Netherlands; Richard Tomassone, Inst. Nat. Agro. Paris, France, N. Scott Urquhart, Department of Statistics, Colorado State University; John Warren, USEPA, Washington, DC., Linda J. Young, Department of Statistics, 
University of Florida; Dale L. Zimmerman, Department of Statistics and Actuarial Science, University of Iowa.

\section{Associate Editors}

Michael Akritas, Penn State U., F. Jay Breidt, Department of Statistics, Colorado State University; Catherine Campbell, Los Alamos National Lab, NM, Loveday Conquest, Center for Quantitative Sciences, U of Washington, WA, Kenny S. Crump, Clement Intl Corp, LA., Richard D. DeVeaux, Department of Mathematics \& Statistics, Williams College, MA; George Flatman, USEPA, NV, Michael E. Ginevan, USDOE, Washington, DC, Colin Goodall, Penn State U, Sharad Gore, Department of Statistics, University of Poona, India; Jeffrey Gove, Northeastern Research Station, USDA Forest Service, NH; Edwin J. Green, Department of Ecology, Evol. \& Nat. Res., Cook College-Rutgers, NJ; Dennis R. Helsel, US Geological Survey, Denver, CO; William Huber, Dames and Moore, PA, Michael L. Lavine, Institute of Statistics \& Decision Science, Duke University, NC; Jean Dominique Lebreton, CNRS/CEFE, Montpellier, France; Walter Liggett, NIST, MD, Ernst Linder, Department of Math and Statistics, University of New Hampshire; Lyman McDonald, Western EcoSystems Technology, Inc., Laramie, WY; B. J. T. Morgan, U of Kent at Canterbury, UK, Wayne L. Myers, Penn State Institutes of Environment, PA; Philip M. North, U of Kent at Canterbury, UK, K. H. Pollock, NC State U, Raleigh, NC, Stephen L. Rathbun, Department of Statistics, Penn State University, PA; M. V. Ratnaparkhi, Wright State U, OH, Jon Schnute, Pacific Biological Station, Canada, Kenneth H. Reckhow, School of the Environment, Duke University, NC; Martin S. Ridout, Institute of Math Statistics \& Actuarial Science, University of Kent, UK; Woollcott K. Smith, Department of Statistics, Temple University, PA; Robert Smythe, George Washington U, Washington, DC, Brajendra C. Sutradhar, Department of Math and Statistics, Memorial University of Newfoundland, Canada; Steven K. Thompson, Penn State U, PA, Lance A. Waller, Rollins School of Public Health, Emory University, GA., Roy W. Whitmore, Research Triangle Institute, NC.

\section{Editorial Collaborators}

H. J. B. Berks, Botanical Institute, U of Bergen, Norway, John Carson, Shaw Environmental \& Infrastructure, Findlay, OH; Chad L. Cross, Landscape Ecology Branch, U.S. EPA, NV; Phillip Dixon, Savannah River Ecology Lab, SC, Pierre Dutilleul, Department of Plant Science, McGill University, Canada; Marie-Josee Fortin, Department of Zoology, University of Toronto, Canada; Qiong Gao, Institute of Resources Science, Beijing Normal University, China; John Haslett, Statistics Department, Trinity College, UK; James Heltshe, U of Rhode Island, RI, G. B. M. Heuvelink, Lab Soil Science and Geology, Wageningen University, The Netherlands; S. A. L. M. Kooijman, Free U, Netherlands, Michael Koehl, Institute of Wood and Forest Science, University of Hamburg, Germany; Bai-Lian Li, Department of Botany and Plant Sciences, University of California; W. K. Michner, Jones Ecological Research Center, GA, Reza Modarres, Department of Statistics, George Washington University, Washington, DC; Bruce Peterson, CH2M Hill, Seattle, WA, Janos Podani, Department of Plant Tax \& Ecology, L. Eotvos University, Hungary; Kenneth H. Reckhow, School of Environment, Duke U, NC, Estelle Russek Cohen, U of Maryland, MD, Allan Stewart-Oaten, 
Biology Department, University of California at Santa Barbara; George Sugihara, Scripps Institution of Oceanography, La Jolla, CA; Mark Taper, Department of Ecology, Montana State University/Bozeman; C. J. F. TerBraak, Agricultural Mathematics Group, DLO, Netherlands, Hans Wackernagel, Centre de Geostatistique, Ecole Natl Superieure des Mines, France

\section{Timely special issues and matching guest editors}

\section{Volume 4, Issue 2, June 1997}

Title: Special issue Environmental monitoring and assessment

Guest Editor: Anthony R. Olsen

Volume 5, Issue 2, June 1998

Title: Special issue on space-time processes in environmental and ecological studies Guest Editor: Peter Guttorp

Volume 6, Issue 1, April 1999

Title: Special issue on statistical design and analysis with ranked set samples

Guest Editors: N. Phillip Ross and Lynne Stokes

Volume 7, Issue 1, March 2000

Title: Special issue on statistical toxicology and toxicological statistics

Guest Editor: Wolfgang Urfer

Volume 7, Issue 3, September 2000

Title: Statistical ecology and forest biometry

Guest Editors: Timothy G. Gregoire and Michael Kohl

Volume 8, Issue 2, June 2001

Title: Special issue on composite sampling

Guest Editors: Barry D. Nussbaum and Richard O. Gilbert

Volume 8, Issue 4, December 2001

Title: Spatial statistics for production ecology and resource conservation Guest Editor: Alfred Stein

Volume 10, Issue 1, March 2003

Title: Special issue on adaptive sampling

Guest Editor: Steven K. Thompson

Volume 10, Issue 3, September 2003

Title: Special Issue on Map Accuracy

Guest Editors: Stephen V. Stehman and Raymond L. Czaplewski

Volume 11, Issue 1, March 2004

Title: Special Institutional Thematic Issue: National Research Center for Statistics and the Environment, University of Washington

Guest Editors: Peter Guttorp and Paul D. Sampson 
Volume 11, Issue 2, June 2004

Title: Special institutional thematic issue: Center for Statistical Ecology and Environmental

Statistics, Penn State University

Guest Editor: G. P. Patil

Volume 11, Issue 4, December 2004

Title: Special Issue on Statistical Methods and Techniques for Analyzing Spatial and Temporal-Spatial Data

Guest Editor: Timothy G Gregoire

Volume 12, Issue 3, September 2005

Title: Special Issue on Environmental Exposure and Small Area Data

Guest Editor: Andrew B. Lawson

Volume 12, Issue 4, December 2005

Title: Special Issue on Environmental Exposure and Small Area Data

Guest Editor: Andrew B. Lawson

Volume 13, Issue 3, September 2006

Title: Special Issue on Analyses of Directional Data in Ecological and Environmental Sciences

Guest Editors: Barry C. Arnold and Ashis SenGupta

Volume 13, Issue 4, December 2006

Title: Special Institutional Thematic Issue: Penn State Cross-Disciplinary Classroom in Statistical Ecology and Environmental Statistics

Guest Editor: G. P. Patil

Volume 14, Issue 1, March 2007

Title: Special Issue on the Application of Spatial Statistics to Agriculture, Ecology, and the Environment (to be continued in Volume 14:2)

Guest Editor: N. Scott Urquhart

Volume 14, Issue 2, June 2007

Title: Special Issue on the Application of Spatial Statistics to Agriculture, Ecology, and the Environment (continued from Volume 14:1)

Guest Editor: N. Scott Urquhart

Volume 14, Issue 3, September 2007

Title: Spatial and Spatio-temporal Modeling in Environmental and Ecological Statistics

Guest Editor: Alan Gelfand

Volume 15, Issue 1, March 2008

Title: Special Issue on the New Development of Statistical Analysis in Wildlife, Fisheries, and Ecological Research

Guest Editors: Chong He and Linda Young 
Volume 15, Issue 3, September 2008

Title: Special Issue on Statistics in Disease Ecology

Guest Editor: Lance A. Waller

Volume 15, Issue 4, December 2008

Title: Special Issue on Spatial Statistics for Boundary and Patch Analysis

Guest Editors: Geoffrey M. Jacquez, Marie-Josée Fortin, and Pierre Goovaerts

Volume 16, Issue 1, March 2009

Title: Special Issue on Modern Benchmark Analysis for Environmental Risk Assessment

Guest Editors: R. Webster West and Walter W. Piegorsch

Volume 16, Issue 2, June 2009

Title: Special Issue on Statistics for Wildfire Processes

Guest Editor: Marcia Gumpertz

Volume 17, Issue 2, June 2010

Title: Special Issue on Surveillance Hotspot GeoInformatics

Guest Editor: G. P. Patil

Volume 17, Issue 4, December 2010

Title: Special Issue on Ranking and Prioritization with Multiple Indicators in Digital Governance and Surveillance Hotspot GeoInformatics

Guest Editor: Ganapati P. Patil

\section{References for individual and collective reflection}

Patil, G.P. (1979). Satellite program in statistical ecology, International Statistical Review 47, 223-228.

Intecol Bulletin, pp. 1-8.

Patil, G.P. (1983). International statistical ecology program, in Encyclopedia of Statistical Sciences, Vol. 4, S. Kotz \& N.L. Johnson, eds, Wiley, New York, pp. 193-194. G.P. Patil (1986). Current statistical ecology initiatives, Biometric Bulletin 3, 3-4.

G.P. Patil (1994). Environmental and ecological statistics (Editorial), Environmental and Ecological Statistics 1, 1-6.

G.P. Patil (1994). A national center for statistical ecology and environmental statistics: a center without walls, in Handbook of Statistics. Environmental Statistics, Vol. 12, G.P. Patil \& C.R. Rao, eds, Elsevier, New York, pp. 9-69.

G.P. Patil, (1995). Silver jubilee of statistical ecology around the world, COENOSES 10, 57-64.

G.P. Patil (1995). Penn State statistical ecology and environmental statistics—25 years, COENOSES 10, 65-74.

G.P. Patil (1995). Editorial: Statistical ecology and related ecological statistics—25 years, Environmental and Ecological Statistics 2, 81-89.

G.P. Patil (1998). INTECOL Working Group on Statistical Ecology, in Intecol 2000, Research Activities, B. Markert, ed., International Association for Ecology. 
G.P. Patil (2000). Editorial: Marching together in the new millennium, Environmental and Ecological Statistics 7, 5-19.

G.P. Patil (2001). Environmental and Ecological Statistics, a Journal entry, Encyclopedia of Environmetrics, A. H. El-Shaarawi and W. W. Piegorsch, eds., Wiley, New York.

\section{Bio in brief of the founding editor-in-chief}

Dr. G. P. Patil is a Distinguished Professor of Mathematical and Environmental Statistics Emeritus in the Department of Statistics at the Pennsylvania State University, and is a former Visiting Professor of Biostatistics at Harvard University in the Harvard School of Public Health.

He has a Ph.D. in Mathematics, D.Sc. in Statistics, one Honorary Degree in Biological Sciences, and another Honorary Degree in Letters. He is a Fellow of American Statistical Association, Fellow of American Association of Advancement of Science, Fellow of Institute of Mathematical Statistics, and Elected Member of the International Statistical Institute, Founder Fellow of National Institute of Ecology and Indian Society for Medical Statistics.

He has been a founder of Statistical Ecology Section of Ecological Society of America, a founder of Statistics and Environment Section of American Statistical Association, and a founder of the International Society for Risk Analysis, International Society for EcoHealth, Society for Syndromic Surveillance and Digital Government Society of North America. He is founding editor-in-chief of the international journal, Environmental and Ecological Statistics and founding director of the Penn State Center for Statistical Ecology and Environmental Statistics.

Dr. Patil has published thirty volumes and three hundred research papers. He has received several distinguished awards which include: Distinguished Statistical Ecologist Award of the International Association for ecology, Distinguished Achievement Medal for Statistics and the Environment of the American Statistical Association, Best Paper Award of the American Fisheries Society, and the Best Paper Award of the American Water Resources Association.

He was a member of the UNEP Science Advisory Panel with Nobel Laureate Mario Molina for the UNEP Division of Environmental Assessment and Early Warning. He recently served on the NSF Panel for Homeland Security and Geographic Information Systems. He has been on the Science Advisory Board of the Spatial Accuracy Symposia. In the recent past, he has served on the EPA Science Advisory Board Regional Vulnerability Assessment Panel and chaired a UNEP Expert Panel for Human Environment Index.

Dr. Patil has been recently principal investigator of a large NSF project on digital governance and surveillance hotspot geoinformatics for monitoring, etiology, early warning, and sustainable development. This has involved upper level set scan based geospatial and spatiotemporal hotspot detection and partial order theory based multicriteria ranking and prioritization with several national and international live case studies. 